\title{
Variaciones de Caracas: el espacio como imagen textual en Celeste Olalquiaga, Yolanda Pantin y Arturo Uslar Pietri.
}

\section{Caracas' Variations: Space as Textual-Image in Celeste Olalquiaga, Yolanda Pantin and Arturo Uslar Pietri.}

\section{Resumen}

En este artículo se pretende analizar cómo los textos de los venezolanos Celeste Olalquiaga, Yolanda Pantin y Arturo Uslar Pietri, cada uno producido en diferentes etapas históricas del país, convienen la representación del espacio como una imagen textual. Esta representación del espacio como imagen textual retrata su contemporaneidad y da cabida a una serie de efectos que van desde la memoria y la configuración histórica de la ciudad, hasta la sugerencia de nuevos modos de ver y sentir en un espacio dado. Para dar respuesta a esta hipótesis se propone estudiar el corpus articulando aspectos teóricos sobre lo visible y lo enunciable (Jacques Rancière), y la idea de la generación de imágenes a partir de la textualidad del relato o el poema (Luz Horne). Se partirá de estas aproximaciones teóricas para argumentar que los textos analizados, valiéndose de una remediación del Realismo, convienen el espacio como una imagen que intenta tanto retratar lo contemporáneo como condensar en lo imaginario los afectos que induce un espacio determinado como la ciudad de Caracas.

Palabras claves espacio, imagen, Celeste Olalquiaga, Yolanda Pantin, Arturo Uslar Pietri.

\begin{abstract}
The purpose of this article is to analyze how a selection of texts by Venezuelan authors Celeste Olalquiaga, Yolanda Pantin and Arturo Uslar Pietri, each produced in different historical stages of Venezuela, represent space as a textual-image. This representation of space as a textual-image portrays both its contemporaneity and a series of effects that stem from memory and the historical configuration of the city, to the suggestion of new ways of
\end{abstract}


seeing and feeling at a given space. To answer this hypothesis, the corpus will be analyzed by articulating theoretical aspects of the visible and the enunciable (Jacques Rancière), and the idea of the generation of images based on the text's textuality (Luz Horne). Taking these theoretical approaches as a starting point, it will be argued that by remediating Realism the study corpus conveys space as an image that both portrays its contemporaneity, and seeks to condense the affects induced by a determinate space such as the city of Caracas.

Keywords space, image, Celeste Olalquiaga, Yolanda Pantin, Arturo Uslar Pietri.

En un texto breve que lleva por título Caracas: Itinerario sentimental, la escritora venezolana Ana Teresa Torres relata una escena en apariencia trivial: “yo era un niña que veía calles, automóviles, personas, árboles, y mi mundo me parecía real, pero en el discurso oral de mi familia Caracas era o el recuerdo de un pueblo que ya no existía o el proyecto de una gran ciudad que estaba por aparecer. Memoria o deseo, nunca presencia” (Torres 22). La anécdota de Torres ilumina claramente una tensión entre la Caracas que la autora experimentaba durante su infancia y la otra Caracas sobre la que hablaban sus familiares, atrapada entre el recuerdo de lo que fue y el advenimiento de lo que será; una tensión con cualidades plásticas, podría decirse, en la medida que parece convenir los espacios como un entramado de imágenes que se ensamblan en la escritura.

En buena medida, es esta tensión presente en las formas de convenir los espacios lo que me propongo analizar en este artículo. Para ello me enfocaré en un conjunto de textos literarios escritos por la ensayista e historiadora cultural Celeste Olalquiaga, la poetisa Yolanda Pantin y el escritor y ensayista Arturo Uslar Pietri como paradigmas que convienen la representación del espacio como imagen textual. Mi punto de partida será que los textos que aquí analizo, escritos en diferentes etapas históricas de la Venezuela del siglo veinte y veintiuno, apelan al espacio como imagen textual para retratar su contemporaneidad y dar cabida a una serie de efectos que van desde la memoria y la configuración histórica de la ciudad, hasta la sugerencia de nuevos modos de ver y sentir en el espacio, aportando distintos puntos de vista sobre un espacio en común: la ciudad de Caracas. Para dar respuesta a esta hipótesis quiero estudiar el corpus articulando 
las propuestas teóricas sobre lo visible, lo enunciable y la frase-imagen, de Jacques Rancière, así como ciertos aspectos desarrollados por Luz Horne en su estudio sobre la generación de imágenes a partir de la textualidad del relato literario. Partiré de estas aproximaciones teóricas para argumentar que los textos de Olalquiaga, Pantin y Uslar Pietri, valiéndose de una remediación del Realismo, convienen el espacio como una imagen que no solo intenta retratar lo contemporáneo, sino que busca condensar en lo imaginario los afectos que induce un espacio determinado como Caracas. ${ }^{1}$

\section{El espacio como imagen textual: lo visible y lo enunciable de Jacques Rancière y el nuevo realismo fotográfico de Luz Horne}

La mirada clasifica y jerarquiza, distribuye y organiza. Para hablar de espacios y de imágenes es necesario hablar de lo visible y su enunciación, de lo que se ve $-\mathrm{y}$ no se ve $-\mathrm{y}$ lo que se dice $-\mathrm{y}$ no se dice-. Jacques Rancière ha dejado claro que las imágenes no deberían entenderse como simples manifestaciones de un medio técnico, sino como operaciones, como "relaciones entre un todo y las partes, entre una visibilidad y una potencia de significación y de afecto que se le asocia, entre las expectativas y lo que las cumple" (Rancière, El destino 25). Tanto en el cine como en la literatura, continúa Rancière, la imagen actúa como una operación que enlaza y desvincula la palabra y su efecto (26). Rancière toma como ejemplo las novelas realistas de Gustav Flaubert —e.g. Madame Bovary - y los films de Robert Bresson - e.g. Al azar de Baltasar-

${ }^{1}$ Si bien no tengo constancia de otros estudios que analicen el espacio como imagen textual en estos autores, convendría señalar, simplemente a modo indicativo, una muestra reducida de trabajos que podrían compartir con mi propuesta, de manera más o menos similar, el interés por proponer aproximaciones a los cruces entre referentes de imagen, texto y espacialidad: ver Luz Horne Una ficción propia. Notas sobre el nacimiento de la ficción contemporánea a partir de Fundido a blanco, de Óscar Muñoz y La experiencia dramática, de Sergio Chejfec; Jens Andermann Paisaje: imagen, entorno, ensamble; Horst Bredekamp "Speech Act and Image Act" (Bredekamp 29-35); María Lucía Puppo y Graciela Queirolo Correspondencias y tensiones de la relación palabra/imagen en la cultura latinoamericana (Puppo y Queirolo 14-22); Begoña Alberti Soto Escribir la imagen: La literatura a través de la écfrasis (Alberti Soto 30-34). 
para señalar que la ambivalencia producto de los procedimientos para convenir las imágenes ${ }^{2}$ produce y extrae el sentido, asegura y deshace el vínculo de las percepciones, las acciones y los afectos (27).

De este modo, Rancière no escatima a la hora de definir una imagen tanto como una "relación simple que produce la semejanza de un original [como un] conjunto de operaciones de lo que llamamos "arte", o sea, precisamente una alteración de la semejanza" (Rancière, El destino 28; entrecomillado en el original). A lo que alude el filósofo francés con lo anterior es al carácter horaciano de la pictoricidad del poema. Es el ut pictura poesis/poesis ut pictura que implica que "el habla hace que se vea, mediante la narración y la descripción, un visible no presente [...], hace que se vea lo que no pertenece a lo visible, reforzando, atenuando o disimulando la expresión de una idea, haciendo sentir la fuerza o la represión de un sentimiento" (Rancière, El destino 33). Esta definición resulta particularmente interesante para el análisis que aquí se propone, pues entender la imagen como una operación implica considerar su efecto desde una perspectiva que abarca la forma y el contenido del texto. En otras palabras, una imagen muestra y dice, y ese mostrar y decir tiene que ver con una relación entre la visibilidad y la significación del arreglo del lenguaje: "Ello quiere decir que las formas visibles hablan y que las palabras tienen el peso de realidades visibles, que los signos y las formas relanzan mutuamente sus poderes de presentación sensible y de significación" (53).

En los textos de Celeste Olalquiaga, Yolanda Pantin y Arturo Uslar Pietri el espacio caraqueño está cifrado por la contingencia y la ausencia. Es un espacio derivado de la memoria, de lo que ha quedado invisibilizado - por las transformaciones sociales, económicas e históricas del país y de la ciudad; por el pasar del tiempo- en el espectro presente y material, y que emerge como efecto

${ }^{2}$ A estos procedimientos me referiré más adelante cuando aborde el nuevo realismo fotográfico que propone Luz Horne. Como se verá, la propuesta de Horne es asumir que hay una serie de ficciones contemporáneas que pintan un fresco de lo contemporáneo abordando temas clásicamente asociados con la estética del Realismo por medio de procedimientos formales de las Vanguardias. Esto enlaza con el carácter ambivalente de la imagen señalado por Rancière, en tanto el procedimiento narrativo para convenir lo que Horne llama lógica de la imagen y efecto de realidad responde a una serie de operaciones tanto formales como de contenido. 
de una evocación, del intento de describir como forma de pintar o fotografiar lo que fue, aunque siempre sujeto a las posibilidades intangibles de la imaginación. En estos ejemplos a los que me remitiré más adelante, el espacio se imagina, y su convención es un proceso que implica al autor en un doble sentido poético, pues lo obliga a encontrar un método o una forma de expresión que haga posible esa descripción de lo invisible. En una línea similar interpreto la idea de la fraseimagen, término acuñado por Rancière para referirse a una forma de pensamiento desligada de los anhelos de pureza de la imagen y del discurso, pensando dentro de una lógica estética que busca reconfigurar las relaciones entre lo visible y lo decible (Soto Calderón 155). De este modo, Rancière define una frase-imagen como:

la unión de dos funciones a definir estéticamente, es decir, por la forma en la que deshacen la relación representativa del texto con la imagen. En el esquema representativo, la parte del texto era la del encadenamiento conceptual de las acciones, la parte de la imagen la del suplemento de presencia que le da carne y consistencia. La frase-imagen perturba esta lógica. (Rancière, El destino 62$)^{3}$

Visto así, la frase-imagen vendría a dar cuenta del entrecruzamiento y la difuminación de los límites entre el decir y el ver, "entrando en un espacio de comunidad sin distancia y sin correspondencia" (63). La frase-imagen tiene la virtud de una sintaxis paratáxica o de montaje —más allá de su interpretación cinematográfica ${ }^{4}$, es una aproximación que logra mostrar - y esto considerado

${ }^{3}$ Para una contextualización de la frase-imagen en el régimen estético del arte y cómo entronca dicha noción con la obra del filósofo francés, véase Jacques Rancière (Rancière, El destino 6067) y Andrea Soto Calderón (Soto Calderón 150-155).

${ }^{4}$ Tampoco creo que Rancière se refiera, al menos no directamente, al montaje en el sentido que le dio Ernst Bloch (Bloch 16-27) cuando describió los procedimientos vanguardistas que emplearon distintos artistas adscritos a la estética del Expresionismo con la intención de capturar lo fragmentario de la realidad, el pasado y el presente. Hay que recordar, como señala Soto Calderón, que "en las articulaciones que [Rancière] propone nos encontraremos siempre con un ejercicio de 'conjunciones disyuntivas' que operan simultáneamente, por lo que no extraña que 
en función del análisis que aquí se propone- la potencia del espacio en su dimensión imaginaria. Es que la frase-imagen es algo más que la unión de una secuencia verbal con una forma visual, ya que en este caso la frase no es lo decible ni la imagen lo visible, sino la unión de estas dos funciones. ${ }^{5}$ En el vocabulario de Rancière: "las palabras ya no prescriben, como historia o como doctrina, lo que deben ser las imágenes. Se convierten a sí mismas en imágenes para hacer mover las figuras del cuadro, para construir esa superficie de conversión, esa superficie de formas-signos" (99). ${ }^{6}$

Pasemos ahora a un aspecto referido a lo formal para emprender el análisis de mi corpus. Luz Horne parte de la concepción del nuevo realismo fotográfico para convenir una idea de discontinuidad y fragmentación narrativa que actúa

el montaje sea un ejercicio constante en el modo de articular sus reflexiones" (Soto Calderón 34; entrecomillado en el original). En este caso, el montaje opera como una metáfora de la conjunción disyuntiva que se efectúa en la idea de la frase-imagen rancièreana.

${ }^{5}$ Así como la definición de la frase-imagen se mueve en un espacio sin límites, su aplicación a nivel analítico tampoco entiende de limitaciones en cuanto al género o las formas del arte: "La potencia de la frase-imagen puede expresarse en frases de novela pero también en formas de puesta en escena teatral o de montaje cinematográfico o en la relación de lo dicho y lo no dicho de una fotografia" (Rancière, El destino 62).

${ }^{6}$ Sobre este punto me interesa señalar que hay otras variantes críticas y teóricas que abordan esta relación entre la imagen y el texto escrito, entre lo que se ve y lo que se dice como categorías al mismo tiempo opuestas y equivalentes: véase "Hablar, no es ver" (Blanchot 61-71) para la conflictiva diferencia entre hablar y ver que formula otros emparejamientos categóricos como velado/desvelado y visible/invisible, así como nociones derivadas del acto de hablar y de ver como la manifestación, la revelación, el afuera o el desvío. Ver también "Los estratos o formaciones históricas: lo visible y lo enunciable (saber)" (Deleuze 75-98), donde Deleuze discute los regímenes y distribuciones de lo visible y lo enunciable, así como sus variaciones como parte de las formaciones históricas, de las épocas. Igualmente, ver John Berger (Berger 734), sobre la interrelación entre ubicación en el espacio, el ver y el usar la palabra para intentar describir lo visto desde una perspectiva estética. No obstante, a pesar de que encuentro equivalencias entre estos trabajos y lo que me interesa discutir aquí, en este artículo me ocuparé en un análisis en el que el espacio se lea como expresado en una imagen textual, que no solo intenta mostrar la contemporaneidad de los textos estudiados, sino que además se encuentra ligado a aspectos de lo imaginario y de la memoria. Por otra parte, la idea de lo contemporáneo y la memoria podría tener cierta resonancia en una serie de reflexiones propuestas por Walter Benjamin sobre el rol histórico-político y estético de las imágenes. Sin embargo, aunque no reniego el vínculo que podría establecerse entre mi propuesta analítica y las reflexiones de Benjamin, descarto establecer un diálogo entre ambas para no desviar la atención del objeto de mi estudio. Con la intención de dejar esa línea de diálogo abierta, propongo ver "Surrealism. The Latest Snapshot of the European Intelligentsia" (Benjamin 143-160), para una aproximación al concepto de imagen en su obra, y Luis Ignacio García (García, Alegoría y montaje 159-164; García, Una política 112-133), tanto para una discusión sobre los conceptos de alegoría y montaje en la obra de Benjamin, como para una aproximación sintetizada del lugar que ocupa y del sentido que tiene la noción de imagen en la obra del filósofo alemán. 
como ajuste del Realismo, partiendo de la lógica de la imagen del texto literario como forma de reflejar la contemporaneidad. ${ }^{7}$ Para Horne, la ambición por representar la propia contemporaneidad en el contexto latinoamericano no es un problema nuevo, sino que viene gestándose desde principios del siglo veinte a partir de la creación de textos ficcionales preocupados por construir mundos verosímiles que den cuenta de las transformaciones a nivel social y urbano (Horne 123-124). Para interpretar esto, Horne toma en cuenta un tipo de narrativa que, a pesar de interesarse por temas realistas, recicla estrategias de la Vanguardia para convenir formalmente un retrato de la época actual (Horne 125). De este modo, aunque el Realismo se mantiene como fuerza temática del texto, la forma de convenir la realidad y su efecto organizativo solo es posible por medio del formato vanguardista. En este tipo de textos es paradigmática la incorporación de la "lógica de la imagen dentro del texto [para generar] una impresión de discontinuidad" (Horne 125) que produce el efecto de realidad necesario para dar cuenta de lo contemporáneo. Esta discontinuidad, sin embargo, no pretende enfatizar la artificialidad de la representación o la imposibilidad de la mimesis que vendrían a ser los objetivos principales de la Vanguardia en oposición al intento socavado del Realismo y el Naturalismo por imitar la realidad-, sino que, por el contrario, se interpreta como una fuerza positiva, una herramienta que permite una aproximación más cercana al mundo verosímil. En otras palabras, lo que Horne plantea es la anulación de la limitante política que opone Realismo y Vanguardia como forma literaria. Si se considera que la ambición por contar lo contemporáneo ha obligado a que el Realismo como movimiento estético haya variado históricamente, se da pues una negociación entre la idea de la literatura como herramienta tanto para decir algo sobre el presente como modo de

7 Si bien el Realismo abarca una serie de preocupaciones más amplias, que van desde el orden moral o el alcance político del Realismo - por ejemplo, considerando el papel aleccionador y disciplinario de la literatura realista del siglo diecinueve (Horne 215, nota 3) - hasta el cuestionamiento del estatuto artístico o literario de las obras alineadas con este movimiento estético, para efectos de este artículo no abordaré, al menos no explícitamente, estas variantes críticas y me centraré en las nociones formales sobre el nuevo realismo fotográfico que propone Horne. 
representación ajustado a las convenciones de su época (Horne 126). De esta manera, se podría interpretar que cada época responde a un determinado régimen artístico para convenir sus propios modos de representación, modificando así las características formales empleadas por los escritores realistas del siglo diecinueve a los del veinte y veintiuno. ${ }^{8}$

Así, Horne indica que la literatura reproduce esta textualidad — la de la lógica de la imagen - en tanto "la imagen se construye verbalmente a pesar de que no aparezca de modo efectivo" (Horne 128). Esta imagen hecha de palabras se entendería en tanto "hace funcionar a los textos como bloques, como unidades compactas que produ[cen] la ilusión de detener la sucesión propia del orden lingüístico" (Horne 128). Como se argumentará más adelante, los textos de Olalquiaga, Pantin y Uslar Pietri, cada uno a su manera, orbitan alrededor de un elemento — por ejemplo, la memoria, lo histórico y lo imaginario, en el caso de Olalquiaga y Uslar Pietri; lo visible y lo enunciable, en el caso de Pantin- que representa, como dice Horne sobre la ficción del argentino Sergio Chejfec, autor paradigmático según la académica del nuevo realismo fotográfico, "un límite para lo simbólico, algo que no puede procesarse a través del lenguaje" (Horne 129). Para expresar lo que el lenguaje no es capaz de expresar, tanto los autores que se proponen en este análisis como los estudiados por Horne, desestabilizan las estructuras poéticas de sus textos imitando la lógica de la imagen, desarrollando "la idea de que las imágenes [...] pueden decir algo que la palabra no puede" (Horne 129). ${ }^{9}$ En los textos de Olalquiaga, Pantin y Uslar Pietri, la estructuración

${ }^{8}$ Dice Rancière: "Significa que las palabras y las formas, lo decible y lo visible, lo visible y lo invisible se relacionan entre sí según nuevos procedimientos. En el nuevo régimen, el régimen estético de las artes constituido en el siglo XIX, la imagen ya no es la expresión codificada de un pensamiento o de un sentimiento. Ya no es un doble o una traducción, sino una manera en que las cosas mismas hablan y se callan. Llega a instalarse, en cierto modo, en el corazón de las cosas como su habla muda" (Rancière, El destino 34).

${ }^{9}$ Es pertinente aclarar que el análisis de Horne se centra en la incorporación de la imagen fotográfica en los textos que estudia. Aunque encuentro interesante esta aproximación, no me interesa desarrollarla en mi análisis debido a que la encuentro restrictiva con respecto a mi corpus de estudio - para una crítica al nuevo realismo fotográfico de Horne ver Silvia Mandolessi (Mandolessi 7-10) - Mi intención, en cambio, es articular una relación entre forma y contenido, de manera que se lea el texto como una frase-imagen, como un intento de concreción imaginaria donde el espacio funciona como una imagen producto del recuerdo, de la 
de esa contemporaneidad narrada o cantada parte de un intercalado de evocaciones, procesos de observación, rememoración del pasado, memorias y formas de ver que condensan espacios determinados en la lógica de la imagen. En este sentido, Olalquiaga traza un mapa imaginario de las transformaciones de Caracas, dialogando con las mutaciones urbanas de la ciudad; Pantin fija su presencia o ausencia en un espacio a partir de diferentes sensibilidades, primordialmente relacionadas con lo que ve y lo que escucha; y Uslar Pietri fractura y enmienda tiempo y espacio en sus viñetas sobre el valle de Caracas volveré sobre estas cuestiones con más detalle en los apartados posteriores-.

Retornando a la operatividad de la imagen textual, Horne indica que se configura una "temporalidad congelada que trae la imagen [que constituye] los textos como una serie de bloques "suspendidos", como si fueran imágenes autocontenidas" (Horne 130; entrecomillado en el original). Se entiende entonces que la imagen textual responde a la idea de un momento temporal condensado que queda fijado en forma de bloque escrito - y que, por otra parte, es necesariamente espacial, como indicaría Martin Heidegger, al definir el concepto de habitación y la asociación inseparable entre el sujeto, el tiempo y el espacio (Heidegger 62-63; 110)-. Esto sirve para "encontrar un modo diferente de decir o mostrar algo del mundo extratextual. Los textos hacen como si pudieran nombrar algo de lo experiencial, lo corporal o material que no se puede decir con palabras de un modo directo" (Horne 138). En otras palabras: "a través de una retórica ontológica en la cual las palabras, sin un soporte subjetivo o lógico que las sostenga [...], aspiran a retener algo de la materialidad del mundo y de las sensaciones básicas. Los textos simulan la idea de que el lector pueda ver, oler, palpar u oír lo que sucede" (Horne 139; cursivas en el original).

\section{Evocaciones inmateriales de lo material: Biografía íntima de la plaza Altamira, de Celeste Olalquiaga}

memoria o de las posibilidades escondidas dentro del mismo espacio en el sentido de lo que se puede ver y no ver al mismo tiempo. 
En Biografía íntima de la plaza Altamira, Celeste Olalquiaga traza una crónica del carácter mutable de la ciudad Caracas, enfocándose en un punto característico del este caraqueño como la plaza Altamira, rebautizada más tarde como plaza Francia, para recrear lo que en su relato llama el ejercicio de su ciudadanía sentimental. Desde las primeras líneas, su narración puede leerse como una serie de fragmentos, de piezas, de imágenes que su memoria evoca partiendo de este punto focal urbano encarnado en la figura de la plaza. Para Olalquiaga, Caracas es una ciudad "signada por la transformación constante, [un] proceso que se da tan cotidianamente que ninguna cara de la ciudad llega a durar siquiera el término de una generación" (Olalquiaga 205). ${ }^{10}$ De este modo, su relato se construirá en base a esa contingencia de lo urbano, a una permutabilidad que mucho tiene que ver también con el mismo juego del recuerdo que convoca la narración para trazar un mapa imaginario de lo visible y lo invisible. ${ }^{11}$ En un sentido formal, lo anterior tiene mucho que ver con "el deseo de retener una cierta materialidad a través del lenguaje, lo cual se da a través de una retórica particular que se utiliza en los textos" (Horne 133). La observación hecha por Horne resulta interesante para indicar justamente el efecto que tiene la recreación del espacio y su presentación en el relato como una imagen textual derivativa del proceso mnemónico, una operación que puede emparejarse a la de la práctica artística de la fotografía, al intento de capturar o congelar un instante determinado. Podría

${ }^{10}$ Esta percepción mutante de la ciudad es lo que ve Josefina Ludmer en el marco de la escritura sobre la ciudad en la América Latina del siglo veintiuno: "Las ciudades latinoamericanas de la literatura son territorios de extrañeza y vértigo con cartografías y trayectos que marcan zonas, líneas y límites, entre fragmentos y ruinas. El nombre de la ciudad puede llegar a vaciarse (como puedan vaciarse la narración o los sujetos de las ficciones) y desaparecer, y entonces el trayecto, el cruce de las fronteras y el vértigo son los de cualquier ciudad o los de "una ciudad"" (Ludmer 130; entrecomillado en el original)

${ }^{11}$ En un artículo, Jacques Lévy hace referencia a la ciudad como "the unplanned program of unexpected experience" (Lévy 33). Para Lévy, lo fascinante de las ciudades no radica en aspectos objetivos u organizativos, sino en la contingencia experiencial que subyace en la relación que la ciudad entabla con los ciudadanos que la habitan. Esta característica le aporta una impronta al mismo tiempo material y virtual (Lévy 44), en tanto desde esta perspectiva la ciudad se entiende como una suma de posibilidades que extiende la invitación a elegir y descartar opciones y formas de experimentarla. En la ficción literaria, la configuración de esta materialidad-virtualidad parece necesariamente ligada a la posibilidad plástica de la imagen: lo escrito es incapaz de reproducir lo material, de manera que lo registra a partir de la sugerencia lingüística: ut pictura poesis/ poesis ut pictura. 
decirse que la narración de Olalquiaga es una recurrencia a esta operación, un intento por tratar de recuperar, en la medida de lo posible, la asociación de la materialidad de los espacios e infraestructuras transformadas en la plaza Altamira y la inmaterialidad de lo que permanece en su propio recuerdo según su experiencia y observación en ese espacio determinado:

Los mapas de las ciudades pueden ser trazados, básicamente, de dos modos: uno es material y plano, aquel que dibuja los contornos de calles y avenidas, ríos y parques, buscando plasmar meticulosamente los elementos físicos de la urbe; el otro es imaginario y dimensional, preocupado solo por aquellos lugares a los que estamos vinculados por la memoria o la necesidad. Cuando atravesamos la superficie de una ciudad conocida, es este último modo el que predomina: desplazándonos por rutas marcadas por la comodidad rutinaria, tendemos a ignorar la mayor parte del paisaje urbano que pasa frente a nuestros ojos. Así, zonas enteras de nuestro diario transcurrir permanecen a oscuras, puntos ciegos que nos acompañan sin que los alcancemos a discernir. Edificios, negocios y carteles no son sino elementos de un escenario frente al cual permanecemos impasibles, dando su presencia por sentada al igual que solemos hacer con el mundo natural que nos rodea. (Olalquiaga 205)

Nótese en el ejemplo citado el peso que gana la segunda perspectiva que señala la narradora, donde el trazado del mapa de la ciudad responde a un hacer imaginario y dimensional. Aquí, el espacio caraqueño es una representación imaginaria, un conjunto de imágenes que pasan frente a nuestros ojos y que solicitan ser discernidas. La imagen que propone el trazado que anuncia Olalquiaga no solo llama la atención por su evidente implicación topográfica, de delimitación espacial o pictórica, de dibujo de contornos, sino también porque, en palabras de Rancière, "al trazar líneas, al disponer palabras o al repartir superficies, uno también dibuja divisiones del espacio común. Es la manera en la 
que, al reunir palabras o formas, uno no define simplemente formas del arte sino ciertas configuraciones de lo visible y lo pensable, ciertas formas de habitar el mundo sensible" (Rancière, El destino 103). Desde este punto de vista, el mismo proceso de escritura le permite a Olalquiaga, en un movimiento imaginario, dar cabida a los recuerdos como formas de edificar un espacio latente en su memoria.

Olalquiaga prosigue su relato destacando que su implicación afectiva con la plaza Altamira no responde directamente a una interacción constante con el lugar; en cambio, la plaza se fijó en su recuerdo como frontera de lo familiar, como línea imaginaria trazada por la convicción de que aquel lugar, desprovisto del valor simbólico que toda plaza suele tener asociado — en otras palabras: lugar para el esparcimiento, embellecimiento del espacio urbano, etc.- , es la marca divisoria que se gesta en la infancia entre el territorio conocido y el desconocido. De hecho, la narradora visualiza la plaza Altamira como área que delimita lo seguro de lo inseguro, el escenario del refugio del escenario del abuso y el miedo, revirtiendo las asociaciones predilectas de las que goza este espacio público: "fue en esta plaza donde, disfrazada de gitana con un vestido anaranjado salpicado de pepas blancas, el pelo recogido en un moño en forma de tomate, enuncié la memoria de un acoso sexual sucedido esa misma tarde en una juguetería de Sabana Grande" (Olalquiaga 206). Es, en suma, una transfiguración del espacio material por efecto de la experiencia y de la mediación del recuerdo: "solo el recuerdo de la narración me queda grabado, permitiéndome de alguna manera conciliarme veinte años después con el hecho de que la plaza Altamira fuera convertida en una entrada metafórica a las profundidades del inconsciente" (Olalquiaga 206).

En el siguiente párrafo, el relato abandona la operación evocativa de la memoria para concentrarse en otra figura, esta vez explícitamente material, que consolida el paradigma de la frase-imagen rancièreana y del nuevo realismo fotográfico de Horne. Olalquiaga se detiene en la estructura del obelisco, el monumento pétreo con forma de pilar que domina y adorna la fisonomía de la 
plaza Altamira. Partiendo de una alusión simbólica, la narradora pone en marcha una alegoría del propio país:

Apuntando con su largo obelisco hacia el cielo, la ahora rebautizada plaza Francia simboliza de alguna manera esa fiebre modernizante que transformó a la Caracas de ciento y pico mil almas en rugiente cosmópolis de un millón de habitantes en menos de tres décadas. Este cambio violento habría de determinar el carácter nacional que esta capital representaba: un país apostado por completo al sueño del progreso, poniendo, cual jugador seguro de ganar, todas sus fichas en el mismo lugar - el recuadro negro del petróleo. Las haciendas cafetaleras y azucareras fueron desapareciendo, cediendo lugar a ese nuevo El Dorado que atraía inmigrantes tanto del exterior como del interior del país a su centro, al corazón mismo de las transacciones financieras y políticas. De un solo salto, Caracas se instaló de lleno en la modernidad. No hubo tiempo para pasar por un proceso de armar un ritmo paulatino de transformación, de pensar en una planificación nacional. (Olalquiaga 207; cursivas en el original)

La forma por medio de la cual Olalquiaga pone de manifiesto la serie de asociaciones que se derivan de su lectura del obelisco pinta como si de un fresco se tratase el lento declive de un país que creyó ver en el petróleo su consolidación definitiva como una nación moderna. En el pasaje, el espacio es un trazado, un paradigma de la frase-imagen que condensa por medio de descripciones y asociaciones la historia económica, social y política de la Venezuela que transitaba del siglo veinte al veintiuno. Más todavía, resulta notable cómo la concreción del tiempo histórico y de los espacios ponen en evidencia la yuxtaposición de forma y contenido en un contexto estético del nuevo realismo fotográfico: estamos ante una síntesis de la lógica de la imagen que busca hacer presente el declive lento de Venezuela. 
La biografía íntima de la plaza Altamira que hace Olalquiaga evoca y escenifica; su lenguaje es el de la visión, el de la persona que mira y observa como forma de experiencia. Podría decirse que el texto de la autora venezolana funciona como una mirada: se posa en distintas figuras, y cada figura notada y luego preservada en la memoria es material fundante para la intelección de la ciudadanía sentimental. De este modo, la pintura de lo contemporáneo que inició con la alegoría desatada por la estructura del obelisco, pasa ahora — se desplaza, posa la mirada en - la casa y su retención como escenario de la infancia. Como ocurre con el recuerdo del intento de abuso, la evocación que hace Olalquiaga del edificio Paraíso — nombre de la residencia donde la narradora pasó sus años infantiles - también es violentada por la alteración del cambio. Así, pues, lo que fuera la posibilidad del recuerdo dulce de la niñez se ve yuxtapuesto con la transformación, años más tarde, del edificio Paraíso en un local comercial para el entretenimiento. Es esto una forma de vaciar el sentido afectivo de aquel espacio al transformarlo en un lugar completamente nuevo: "Pero el edificio Paraíso cambió, y en grande: despojado de su plácida dignidad, fue transformado de la noche a la mañana en el refulgente Family Center Yamín, una especie de caja de cristal verde" (Olalquiaga 207; cursivas en el original). Esta yuxtaposición o montaje, que es un efecto tanto formal - en tanto la narradora se vale de esa dialéctica narrativa de contraponer lo pretérito y lo presente- como de contenido - como ocurre con el resto del texto: el discurrir de la narración tiene como eje el trazado del mapa invisible de la ciudadanía sentimental - permite intuir el intento de hacer perdurar lo que solo es visible en la memoria. Es decir, la dinámica narrativa del texto solicita ese discurrir entre lo que es y lo que fue no solo en el sentido de la materialidad cambiante de lo urbano, sino también en el mismo aspecto de la experiencia corporal y de lo sentimental por parte de la narradora, que hermana experiencia y afectividad infantil, adolescente y adulta con el espacio del antes y el ahora: "logré ubicar en una esquina del segundo piso [en el Family Center Yamín] el lugar de mis fotos de infancia, ahora un lago con un puentecito de plástico sobre el cual rezaba en grandes letras Isla de la Fantasía. 
Quizás este sea el final más apropiado para la nostalgia” (Olalquiaga 207; cursivas en el original). ${ }^{12}$

Para la narradora, el espacio parece ser una forma de verosimilitud, un testimonio que es necesario hacer constar y señalar, mirar y enunciar. Es que la sensación que produce la lectura del texto de Olalquiaga es cercana a la experiencia que describe Horne cuando habla de las ficciones del nuevo realismo fotográfico: "[Estos] textos hacen como si pudieran retener ciertos restos materiales o reales" (Horne 135; cursivas en el original). Estamos ante un texto literario que intenta salir del lenguaje para ofrecer una imagen que conserve algo de lo objetual. Esto obliga a volver al primer párrafo que abre la crónica de Olalquiaga, y que delimita los espectros del trazado del mapa de la ciudad material y de la ciudad sentimental. Pero también invita a reflexionar sobre la frase-imagen que se va desplegando a lo largo del relato o, mejor dicho, del trazado por medio del cual Olalquiaga nos permite ver, por ejemplo, otra alusión al lento deterioro de Venezuela. Esta forma de ver lo contemporáneo toma como punto de partida la destrucción producto del terremoto de Caracas del año 1967. La narradora alude a los estragos causados por la hecatombe prestando particular atención a la importancia modernista que se vino abajo con los edificios destruidos tras la catástrofe natural: "siendo durante mucho tiempo los nombres de los edificios caídos [...] triste recordatorio de cuán rápido se derrumbaron los sueños montados sobre terrenos inciertos" (Olalquiaga 208). La sutileza poética de esta frase-imagen, que encarna en la destrucción de símbolos del modernismo urbano la inestabilidad venezolana, logra la concreción del espacio como imagen textual de lo contemporáneo, porque en ella, como diría Rancière, “[las palabras]

\footnotetext{
${ }^{12}$ En este pasaje se da otro nivel de lectura. Tomando como punto de partida la idea de las fotos de la infancia, Olalquiaga pone en marcha el nombramiento de algo que no puede decirse, aludiendo a una prueba o a una manera de documentar lo que una vez fue el pasado - la infancia en el edificio Paraíso - comparada con el presente — la visita al ahora Family Center Yamín-. En este sentido, como diría Horne, el comentario de la fotografía produce "una discontinuidad, una interrupción en la coherencia narrativa, se genera la ilusión de eliminar la sucesión característica del orden lingüístico y la estructura narrativa se "desestabiliza" [...] permitiendo nombrar algo de lo que no se puede decir de un modo directo" (2012: 132; entrecomillado en el original).
} 
se convierten a sí mismas en imágenes para hacer mover las figuras del cuadro [o del texto], para construir esa superficie de conversión, esa superficie de formassignos" (Rancière, El destino 99).

Cerca del final del texto, la narradora ofrece una última muestra de la desintegración social de la ciudad, comentando sobre la inauguración del metro de Caracas y la adaptación de la plaza Altamira como parte de su integración al sistema de transporte subterráneo caraqueño:

No es por sus costados, sino en su centro mismo, por donde la plaza Altamira se abrió al futuro, transformando el espejo de agua en que la ciudad se reflejaba en una larga cascada que baja hacia sus entrañas $[\ldots]$ el lugar donde la Caracas del siglo XX se encontró a medio camino con su sucesora [...] La entrada a la estación del metro Altamira podría verse como una especie de gruta contemporánea a la que descendemos como quien se adentra en una expedición decimonónica en busca de universos insospechados, solo que en vez de proyectar el mundo de la superficie, encontramos aquel, mucho más guardado, del inconsciente. $\mathrm{Y}$ es que desde su construcción en 1983 el Metro de Caracas mostró un carácter cívico desconocido en nuestra ciudad: aquel del orden y la eficiencia, un respeto y cuidado que nos eran casi totalmente foráneos y delataban cierto deseo y capacidad colectivos de someterse al control. Basado en el asombro y la vigilancia, este mundo utópico languideció bajo el peso de la familiaridad y ese gesto autodestructivo que lleva a los caraqueños a ignorar los beneficios comunes de la propiedad pública, comprobando así que los paternalismos autoritarios no sirven para modificar conductas: tan solo reprimen lo que, una vez aflojado, se desata con doble furor. $\mathrm{Ni}$ siquiera en metro el futuro de la Caracas moderna pudo llegar a su destino. (Olalquiaga 209) 
Este cuadro de lo contemporáneo encierra en sí la potencia reflexiva del texto de Olalquiaga. Es un intento por darle cabida a un efecto de realidad o de materialidad que busca salir de la representación simbólica sin caer en lo autorreferencial. Señala Horne que:

la estructura representacional que en algunos textos realistas organiza el sentido de la historia y da una impresión de didactismo, se transforma aquí [...] en una estructura "frágil" y "volátil" que, sin embargo, relaciona contenidos con un gran anclaje referencial o, por lo menos, con una referencialidad que se simula como tal. (Horne 142; entrecomillado en el original)

En efecto, Olalquiaga no pretende convenir un texto moralista, didáctico o piadoso. En cambio, su forma evita las convenciones clásicas del Realismo y se mueve como el trazado topográfico del mapa imaginario, como la mirada atenta que se ha fijado en el mundo y ha registrado esa experiencia imaginaria en la memoria. La fragilidad y volatilidad de lo recordado desata la dialéctica entre lo material y lo inmaterial, y esta yuxtaposición encuentra su máxima expresión en el intento por condensar lo visto con lo enunciable.

\section{Abrir los ojos, escuchar los espacios: A veces, de Yolanda Pantin}

A diferencia del texto de Olalquiaga, A veces, poema de Yolanda Pantin, no pretende trazar el mapa invisible de la ciudadanía sentimental. Podría decirse que el interés de la poetisa caraqueña está puesto en darle sentido a un amasijo de prácticas sensoriales producto de la experiencia en el espacio. Desde el inicio, el poema de Pantin propone una dialéctica entre lo visible y lo invisible, y entre lo que se escucha y lo que se calla. Las primeras líneas atestiguan lo anterior: "no sé dónde estoy,/como esta tarde en Caracas./ Escucho llover/ cuando Dennys me 
dice:/ «Así fue en el deslave»" (Pantin 425; entrecomillado y cursivas en el original). La dinámica entre ver y escuchar será una constante en todo el poema, pero también lo es el oscilar del sujeto lírico entre la dificultad que tiene para precisar el lugar donde se está, y ofrecer, al mismo tiempo, anclajes en lo real -o efectos de realidad - que establezcan conexiones realistas con el mundo. Esto no es solo evidente en la mención reiterativa de Caracas - $\mathrm{O}$ de Turmero, del municipio caraqueño de Chacao o del cerro El Ávila, más adelante en el poema, sino también en la frase que le comunica Dennys y su referencia clara a la Tragedia de Vargas del año 1999, en la cual miles de venezolanos perecieron y otros tantos resultaron damnificados.

La potencia del poema está en su situarnos en el espacio por medio de la puesta en escena de imágenes textuales. Esto no quiere decir que la autora recurra a la mera enunciación de la ciudad, del jardín o de la casa para convenir este efecto locativo, sino que la frase-imagen que comunica la voz de Dennys — “Así fue en el deslave" (Pantin 425) - reconfigura completamente el sentido de los espacios que irán emergiendo a lo largo del poema. En otras palabras, la mención del deslave, y todo lo que el evento asociado a la acción codifica en el imaginario venezolano contemporáneo, signa lo que el sujeto lírico ve, escucha y recoge en el poema: "Llueve de tal forma/ como nunca lo había visto. El ruido [...] me hunde en los terrores del sueño/ como pasa con los años. No duermo" (Pantin 425); o "Yo me echo a reír/ ya que todo parece caer sobre nosotros:/ el cielo, y el Ávila. Siento pánico. A veces/ me levanto en la noche, y en medio del desastre,/ no sé dónde estoy./ Me cuesta retirar/ la membrana pegajosa/ que aúna las realidades. Así, parece igual/ estar dormida que despierta” (Pantin 426).

En su forma de convenir lo poético, es un texto que puede responder a las dinámicas del nuevo realismo fotográfico de Horne: hay una condensación de imágenes fragmentarias que no pretenden ser necesariamente simbólicas o innecesariamente intimistas, sino indicar con señales un retrato del sentir contemporáneo (Horne 142). Es que, más todavía, el poema de Pantin puede leerse en clave rancièreana si se interpreta como la abstracción de "un esquema 
fundamental de los espectáculos de la naturaleza o de los accesorios de la vida, y los transforma en algunas formas esenciales. Ya no son espectáculos que se ven ni historias que se cuentan, sino eventos-mundo, esquemas de mundo" (Rancière, $E l$ destino 105). En este sentido, las formas esenciales de Pantin no solo implican la cuestión de lo que se experimenta, sino también de dónde, cómo y de qué manera se experimenta: su esquematización del mundo y del sentir encuentra su dinamismo formativo en el ver y el escuchar en el espacio, reconociendo el sentido último del estar-en-el-mundo heideggeriano. ${ }^{13}$ Para la voz poética, por ejemplo, lo que se experimenta en el espacio, lo que se ve y lo que se escucha puede ser aterrador: "Miro/ con mis hermanos el fluir de las aguas/ que levantan los carros cuando pasan,/ creando olas inmensas, nos parecen,/ por sobre las aceras./ Es el agua que igual baja/ por las avenidas umbrosas/ de esta parte, en Caracas,/ cuando arrecia el aguacero" (Pantin 425). Pero también puede resultar en lenitivo para el alma: "Pero abro los ojos y voy a la cocina,/ y en la nevera miro los afanes de Jimena/ para el almuerzo de mañana en el banco,/ y como todas las noches, la lonchera de Efraín,/ abierta, junto al fregadero. Son las cosas/ que de una forma humana me consuelan,/ como ver sobre el sofá dormir a Loqui” (Pantin 426) o "Escucho detrás de las puertas/ en el pasadizo/ el ruido de los ventiladores./ Me apacigua el roce metálico/ que hacen las aspas y percibo/ nítido en la madrugada" (Pantin 426). De este modo, el poema podría leerse como un intento por balancear las experiencias que nos procuran determinados espacios: la escena de la destrucción ocasionada por la naturaleza encuentra su contraparte en la escena familiar de la casa, donde las formas esenciales también guardan otra manera de dar cabida al espacio como una imagen textual. ${ }^{14}$

\footnotetext{
13 "El espacio está fragmentado en los lugares propios. Pero esta espacialidad tiene [...] su unidad propia. El "mundo circundante" no se inserta en un espacio previamente dado, sino que su mundanidad específica articula [...] una determinada totalidad de lugares propios circunspectivamente ordenados. Cada mundo particular descubre siempre la espacialidad del espacio que le pertenece. Dejar comparecerlo a la mano en su espacialidad circunmundana no es ónticamente posible sino porque el Dasein mismo es "espacial" en su estar-en-el-mundo" (Heidegger 110; entrecomillado en el original).

${ }^{14}$ En una línea interpretativa similar, Dámaris Vásquez Suárez sostiene que la poesía de Pantin "se ha orientado hacia la construcción de un temperamento poético que explora con sentido de
} 
Los últimos versos del poema dan la impresión de alejarse de la temática general que subyace al texto y romper con el sentido que se viene configurando desde el inicio. Aquí, si bien la fragmentación vuelve a ponerse en práctica y la estética realista se diluye en los efectos formales y expresivos de la Vanguardia, no es motivo alguno para desprenderlo completamente de la temática general que se puede interpretar en la lectura del poema. Es decir, en estos versos finales no nos encontramos con el ruido o el espectáculo destructivo de la lluvia; tampoco con la escena paliativa del hogar y su sensación de calma. Estos últimos versos hablan, en cambio, del encuentro decepcionante con algún funcionario, probablemente público —-"Escucho la voz del funcionario:/ Así deben ser: disconformes. Qué cinismo/ el de su argumentación, es limpia/ y corta igual/ que la hoja de un cuchillo" (Pantin 427)_, y el relato de una fábula que le cuenta un hombre llamado Carlos —_Ayer, por ejemplo, Carlos/ me contó una fábula:/ Cuenta la historia de una doncella/ que convierte la torre donde vive/ con sus fantasmas, en un puente/ tendido sobre el abismo" (Pantin 427)—. En estos casos, la variación temática no incurre en la desvirtuación total del sentido, todo lo contrario: la representación del espacio como imagen textual sigue presente, pero ya no como catástrofe natural sino como catástrofe social encarnada en el cinismo del funcionario; así como también ocurre con el sosiego del hogar y de lo familiar que se trasplanta a la visión o reflexión profunda que desencadena el relato del posible amigo, esa fábula que, como sucede con toda ficción, es una forma de ficcionalizar la realidad para poder pensarla. ${ }^{15}$ En A veces, lo visible y lo invisible, lo dicho y lo callado son formas de esquematizar la realidad, de presentar los

universalidad espacios que oscilan entre la muerte y otras formas de la ausencia [...]. Fundamenta su poesía en la fragmentación de la subjetividad, en una autoconciencia problemática, un YO [sic.] frágil y quebradizo cuya experiencia de la relación pasa por el tamiz. de la sensibilidad" (Vásquez Suárez 86-87; mis cursivas). Me interesa particularmente la mención de la 'universalidad de los espacios', las 'otras formas de ausencia' y la 'experiencia de la relación pasada por el tamiz de la sensibilidad' en tanto resuenan en las formas de ver y enunciar que cifra el poema de Pantin.

15 "Lo real debe ser ficcionalizado para ser pensado. [En este sentido, las ficciones se construyen como] redistribuciones materiales de signos y de imágenes, de relaciones entre lo que vemos y lo que decimos, entre lo que se hace y lo que se puede hacer" (Rancière, El reparto 61-62; cursiva en el original). 
efectos que tiene el espacio sobre la propia experiencia. En su poema, Pantin intenta capturar estas sensibilidades a través de la articulación del espacio como una imagen que intenta retirar "la membrana pegajosa/ que aúna las realidades" (Pantin 426).

\section{Viñetas y espacios yuxtapuestos de lo pasado y lo contemporáneo: Caracas de Venezuela, de Arturo Uslar Pietri}

Es Caracas de Venezuela, de Arturo Uslar Pietri, el texto que más semejanzas formales guarda con las formas literarias de la Vanguardia. La narración se divide en cinco vignettes —El valle, Los barrios, El crecer, Los mangos, Tres notas-, presentando distintos cuadros que pintan épocas, ciudadanos ilustres e historias de la formación y la vida en Caracas. Más todavía, la clara fragmentación espacio-temporal que hila las distintas viñetas se refuerza con cómo Uslar Pietri lleva al límite las formas literarias combinando descripciones detalladas al puro estilo del Naturalismo y el Simbolismo o entrecruzando el relato historiográfico con la crónica y la autobiografía. Visto así, las estrategias narrativas empleadas por el escritor venezolano pueden interpretarse como herramientas pictóricas, brochas, pinceles y lápices que trazan, por medio de la enunciación de imágenes textuales que dan cuenta de una Caracas al mismo tiempo histórica y personal, la configuración del espacio. Este es el caso concreto de la primera vignette, El valle, donde la descripción detallada nos procura el efecto de la mirada pictórica o fotográfica:

El valle de Caracas es como el cuenco de dos manos unidas amorosamente para retener un agua de gracia [...] La luminosidad extraordinaria de su cielo da a las formas y los matices de las cosas una calidad inolvidable. Los árboles, los techos, las nubes están henchidos y cubiertos de luz viva. La luz de Caracas tiene un gran telar de hacer 
tapices en la tendida urdimbre del cerro del Ávila. Cubierto de ásperas manchas de bosques y de suaves lampos de hierba, desarrollando en quiebras, combas, arcos y masas poderosas y equilibradas, el cerro tutelar de la ciudad cambia de apariencia a cada instante del día. Con los primeros rayos del sol se alza como una ola de rosa de cornalina; más tarde, entre el ocre y el verde no deja de agitarse y de variar, atenuando y acentuando alternativamente sus formas. Al punto del mediodía, bajo el cielo limpio y encendido de sol, parece una pirámide oscura. Con la tarde comienzan a tocarlo los matices del azul. Primero son algunas breves manchas en las hondonadas; luego son grandes lienzos de la cuesta que azulean como el fondo de un viejo gobelino. Los contrastes de azul se hacen más varios y sensibles cuando alguna nube blanca viene a encallar sobre la cresta del monte. En la hora del crepúsculo se llena de violetas, amatistas y algunos toques de púrpura viva. Limpio y sin peso entra en la noche. La luna lo convierte en un gran yacimiento del azul sideral que flota en el espacio. (Uslar Pietri 57)

El espacio se nos presenta entonces como una configuración variable de luces, colores y formas, procurando una serie de imágenes para convenir la geografía capitalina. Como la escritura es incapaz de retener lo material, de registrarlo exactamente como lo hace, por ejemplo, la fotografía o el video, el lenguaje promueve una serie de asociaciones lingüísticas, de imágenes verbales que permiten dar cuenta de la configuración espacial del valle de Caracas y el cerro El Ávila. Esta manera de ver el mundo como una gran pintura profusa en detalles no es ajena a la escritura de Uslar Pietri, quien "ve en la historia la explicación de nuestro presente y nuestro futuro. Explicación ésta rica en posibilidades, abierta al porvenir" (Tinoco Guerra 104). No extraña, pues, que el discurrir de Caracas de Venezuela imponga un diálogo entre el pasado, el presente y el futuro próximo, y que para proporcionar ese fresco contemporáneo del presente horneano el venezolano parta de los acontecimientos históricos 
enmarcados dentro del espacio caraqueño. Así ocurre en la siguiente viñeta del texto, Los barrios, donde Uslar Pietri traza mapas superpuestos señalando diferentes puntos clave de la ciudad para dar cuenta de la primera configuración urbana de Caracas y sus posteriores cambios. Si bien la narración no es rica en descripciones como el ejemplo citado más arriba, su función es, en cambio, condensar el sentido en palabras determinadas — lo tradicional y la ciudad, por ejemplo - para enfatizar la dimensión del cambio. Se da entonces una concreción espacial y temporal que tiene el efecto de encerrar, en escasos párrafos, la evolución urbana e histórica de la capital de Venezuela:

La vieja ciudad era más bien una aglomeración de barrios. Cada uno de ellos tenía su carácter propio, su iglesia, su patrono, sus costumbres características y sus particulares tradiciones $[. .$.$] Con el crecimiento de la$ ciudad esa vida aislada y peculiar de los barrios fue desapareciendo. El desarrollo del este, la construcción del Silencio y de la avenida Bolívar, rompieron aquel equilibrio tradicional. Surgieron otras dimensiones, otras relaciones y otro equilibrio interno de la ciudad. Pero mucho de aquel carácter peculiar de los viejos barrios ha quedado en ella, dándole sabor y color. (Uslar Pietri 58-59)

Un objetivo similar al del último ejemplo ocupa a la tercera vignette, El crecer, que pone a dialogar, esta vez con mayor detalle, lo historiográfico con la crónica, presentando de este modo el paso de la Caracas-villa a la Caracasmetropolitana. Lo interesante de esta dinámica narrativa es que Uslar Pietri se vale de ese trazado espacial de Caracas para comunicar la historia del valle, para hacernos partícipes de una suerte de alteración espacial y social que van de la mano. En El crecer, Uslar Pietri demuestra que un espacio en teoría fijo —en este caso Caracas - es en realidad un producto inestable, una suma y superposición de espacios anteriores, cada uno albergando eventos y transformaciones sociales, económicas y políticas que no pueden desligarse las unas de las otras. Con esto, el 
texto imita el trazado de un mapa histórico y costumbrista de la ciudad de Caracas, disponiendo dialécticamente al valle con el indio y el colono (Uslar Pietri 59), a la ciudad naciente con las proezas de Simón Bolívar (Uslar Pietri 60; 65), a la Caracas nocturna con las leyendas de fantasmas (Uslar Pietri 61) o a la Caracas de 1930 con la irrupción del petróleo que marcaría un antes y un después en la historia del país (Uslar Pietri 61). Esta topografía no escatima en su afán por establecer el nexo entre el espacio y lo histórico; es como si cada esquina de la ciudad tuviera su correlato en lo humano y viceversa:

Si hubiera de dialogar su sombra con las de los otros añorantes de las otras Caracas sucesivas, no podría pasar de nombrar el alto monte que después se llamó Ávila. Todo lo demás ya había ido cambiando para cada uno de los otros. [...] Cuatro emociones verdaderas, nacidas en cuatro momentos de una realidad que no ha cesado de cambiar, y que, en cierto modo, murieron con los hombres que las supieron sentir profundamente. La emoción que del valle de Caracas pudo tener Fajardo era poco diferente de la que pudieron experimentar Tamanaco o Guaicaipuro. Una emoción extraña y ajena a casi todos los elementos que ponían ternura en la pluma del historiador Oviedo. De la que ya difieren en cosas esenciales la de Miranda, y aún más la de Pérez Bonalde. (Uslar Pietri 63-64)

Y esa mirada histórica es, necesariamente, una mirada que siempre entronca, que se solapa con la mirada propia, con la experiencia personal en ese espacio que es la ciudad cambiante:

Los que hoy vivimos o pensamos en Caracas pertenecemos a la era del mango. Una era hermosa y significativa que acaso ya está tocando a su fin. Tal vez ya estén naciendo los elementos de otra emoción distinta del valle de Caracas. De otra visión y de otra comprensión. [...] La verdad es 
que estas emociones sucesivas no llegan a reemplazarse totalmente, sino a sobreponerse y, en cierto modo, a mezclarse. En nuestra visión actual están presentes elementos de Fajardo y de Oviedo y de Pérez Bonalde. Y esta emoción es la que habrá de transmitirse, como fondo común de identidad, a la impresión que del mismo terruño habrían de tener mañana los que lo conozcan modificado con nuevos elementos. (Uslar Pietri 64)

En otro orden de ideas, Caracas de Venezuela construye también una frase-imagen que se gesta en la exposición del exilio y el deseo por aprehender la patria y la ciudad desde lo extranjero. Es la imagen del exiliado una manera de entender la alteración misma del país, de comprender la relación afectiva que imbrica al hombre con el espacio. Así, Uslar Pietri comienza su última vignette, Tres notas, contando la relación de añoranza que mantuvieron con Venezuela exiliados ilustres como José de Oviedo y Baños, Bolívar o Teresa de la Parra: "Ha descubierto que no es sino una caraqueña [en referencia a de la Parra], se le ha revelado la belleza profunda de todo aquello que creía haber conocido, y no espera y ansía sino: «llegar otra vez a tener a la vista el Ávila»” (Uslar Pietri 66; entrecomillado en el original).

Las últimas líneas del texto viran hacia un relato más cercano a lo autobiográfico. El narrador relata su experiencia como retornado a Venezuela tomando nuevamente la figura de El Ávila como destinatario de sus afectos. Se escribe otro bloque en el que se condensa tiempo y espacio: "De todas esas angustias estaba hecha la emoción de mi regreso [...] Todo me iba siendo devuelto con un tinte y un sonido de encantadora novedad. Y, lo primero, la luz del valle de Caracas [...] En la luz estaban las paredes, y el techo oscuro de la Iglesia de Chaco, y los cedros y los mangos. Y tantos pájaros que me cantaban canciones de mi infancia" (Uslar Pietri 67). La frase-imagen que contiene la luz del valle de Caracas conjuga la constitución del mismo texto: es la sumatoria del hombre reconociéndose en su propio espacio, del narrador revelándose a sí mismo como caraqueño, como receptor de la luz del valle de Caracas: "La emoción del 
reencuentro está tejida como un tapiz de todos estos hilos de color y de todos estos nudos. Yo la repaso ahora en el recuerdo sin fatigarme de volverla a ver" (Uslar Pietri 67-68). Lo que resulta más llamativo en esta frase es que nos señala la fundación sugestivo-estética de la realidad; esto es, el efecto estético que procura esa aprehensión del espacio propio. Lo que el texto nos hace ver a través de lo escrito es el arreglo íntimo de los poderes discursivos de lo no-verbal —es decir, de aquello que es imposible de expresar lingüísticamente y que se funde en el intento por hacerse notar a través de la imagen textual-, de modo que la experiencia de lo material, de la ciudad en general que intenta describir el narrador a lo largo de cada una de sus viñetas, es un acto de fascinación sublime donde la experiencia del espacio se ve caracterizada por una participación emocional que el individuo ambiciona comunicar. ${ }^{16} \mathrm{El}$ intento por dar cabida a lo anterior resulta en el producto textual, en esa aspiración horneana por retener algo de la materialidad del mundo y de las sensaciones básicas, simulando textualmente la idea de que el lector pueda experimentar lo que el narrador relata (Horne 139).

\section{Reflexiones finales}

Los textos de Celeste Olalquiaga, Yolanda Pantin y Arturo Uslar Pietri convienen diferentes formas del espacio recreado como imagen textual, intentando mostrarnos lo contemporáneo según la época en la que cada texto se

\footnotetext{
${ }^{16}$ Para Jürgen Hesse, la ciudad representa una imagen estética de los diferentes estilos de vida que confluyen en ella. Hesse remarca la preponderancia de lo estético y de la experiencia en el espacio mediada por la imagen relacionada intrínsecamente con la percepción y la apropiación: "The perception of aesthetic forms, figures, and situations of representation [in the city] can not be reduced either to vision or to symbolic understanding, but is deeply rooted in the [...] ways of perception and appropriation [...] which build up patterns of relationships that regulate individual and social life with respect to the economy, politics, and culture" (Hesse 51). Las distintas Caracas que se configuran en el texto de Uslar Pietri juegan con estas formas de mirar, percibir y apropiarse —en este caso por vía de la escritura y lo histórico - de un espacio compartido y, al mismo tiempo, diferencial.
} 
emplaza. La forma literaria de estos ejemplos encierra determinados conceptos del nuevo realismo fotográfico, pero no se abstiene o ajusta a las limitantes que las reflexiones de Luz Horne pueden imponer. Esto no quiere decir que las temáticas del Realismo no ocupen la estructuración de lo que se narra o que su abordaje literario no parta de la conjugación de las formas de narrar de la Vanguardia; esta convención de contenido y forma es notable en el corpus. A lo que me refiero, en cambio, es a que estos textos no persiguen únicamente efectos de realidad o formas de aprehender la materialidad del espacio, sino que los une la necesidad de hablar sobre el espacio como figura estructural para relatar sus experiencias y sensibilidades, y la consecuente dificultad que le viene añadido al intento de expresarlo correctamente por ser este un espacio inmaterial -el del pasado, el de la memoria, el que queda arrasado por el desastre natural, el de la cambiante experiencia personal-.

Visto de este modo, al leer lo relatado por Olalquiaga y Uslar Pietri o el poema de Pantin no estaríamos pensando la expresión del espacio como imagen textual como una forma de indexación o documentación de lo real; por el contrario, el gran dilema de esos espacios que intentan describir los autores venezolanos es que son espacios que existen como presencia efímera en la memoria o el recuerdo, que se evocan sometiendo cualquier forma de lo verídico a la contingencia de la observación y del recuerdo, a la posibilidad latente de lo que era frente a lo que es. El espacio como imagen textual se inserta en las dinámicas que nota Rancière entre lo decible y lo visible, entre lo callado y lo invisible, promoviendo frases-imágenes que redimensionan el sentido de lo que se cuenta. Rancière señala que esta función literaria ya no le interesa trazar las delimitaciones impuestas por la mimesis y la poiesis, sino que se concentran en hacernos ver de otra manera: "el problema no es oponer la realidad a sus apariencias. Es construir otras realidades, otras formas de sentido común, es decir, otros dispositivos espacio-temporales, otras comunidades de las palabras y las cosas, de las formas y las significaciones" (Rancière, El espectador 102). En este sentido, las voces en los textos de Olalquiaga, Pantin y Uslar Pietri son 
paradigmas del sujeto que observa y registra el espacio a modo de una imagen que yuxtapone el pasado con la continuidad de un ahora que se evanece.

\section{Bibliografía}

Alberti Soto, Begoña. "Escribir la imagen: La literatura a través de la écfrasis." Literatura y Lingüística, núm. 33, 2015, pp. 17-38.

Andermann, Jens. "Paisaje: imagen, entorno, ensamble." Orbis Tertius, vol. 13, núm. 14, 2008.

http://www.orbistertius.unlp.edu.ar/article/view/OTv13n14a01/3691. 31 marzo 2018.

Benjamin, Walter. "Surrealism. The Latest Snapshot of the European Intelligentsia." One-way Street and Other Writings. Traducción de J. A. Underwood, Penguin Books, 2009, pp. 143-160.

Berger, John. Ways of Seeing. BBC y Penguin Books, 1972.

Blanchot, Maurice. "Hablar, no es ver." El diálogo inconcluso. 1969. Traducción de Pierre de Place, Monte Ávila editores, 1993, pp. 61-71.

Bloch, Ernst. "Discussing Expressionism." Aesthetics and Politics. Theodor Adorno, Walter Benjamin, Ernst Bloch, Bertolt Brecht, Georg Lukács. 1977. Verso, 2007, pp. 16-27.

Bredekamp, Horst. "Speech Act and Image Act." Image Acts. A Systematic Approach to Visual Agency. 2007. Traducción y edición de Elizabeth Clegg, De Gruyter, 2018, pp. 29-35.

Deleuze, Gilles. "Los estratos o formaciones históricas: Lo visible y lo enunciable (saber).” Foucault. 1986. Traducción de José Vázquez Pérez, Paidós, 1987, pp. 75-98.

García, Luis Ignacio. “Alegoría y montaje. El trabajo del fragmento en Walter Benjamin." Constelaciones - Revista de teoría crítica vol. 2 , 2010, pp. 158-185.

—_ "Una política de las imágenes: Walter Benjamin, organizador del pesimismo". Escritura e imagen, vol. 11, 2015, pp. 111-133.

Hasse, Jürgen. "Emotions in an Urban Environment: Embellishing the Cities from the Perspective of the Humanities." Cities and Fascination. Beyond the Surplus of Meaning, editado por Heiko Schmid, Wolf-Dietrich Sahr y John Urry, Ashgate, 2011, pp. 49-74.

Heidegger, Martin. Ser y Tiempo. 1927. Traducción de Jorge Eduardo Rivera, Editorial Universitaria, 1997.

Horne, Luz. "Una ficción propia. Notas sobre el nacimiento de la ficción contemporánea a partir de Fundido a blanco, de Óscar Muñoz, y La 
experiencia dramática, de Sergio Chejfec". Cuadernos de Literatura, vol. XX, núm. 40, 2016, pp. 89-102.

. "Fotografía y retrato de lo contemporáneo en El aire y otras novelas de Chejfec." Sergio Chejfec: Trayectorias de una escritura. Ensayos críticos, editado por Dianna C. Niebylski, Instituto Internacional de Literatura Iberoamericana y Universidad de Pittsburgh, 2012, pp. 123146.

Lévy, Jacques. "The City is Back (In Our Minds)." Cities and Fascination. Beyond the Surplus of Meaning, editado por Heiko Schmid, WolfDietrich Sahr y John Urry, Ashgate, 2011, pp. 33-48.

Ludmer, Josefina. "La ciudad como isla urbana." Aquí América Latina: Una especulación. Eterna Cadencia Editora, 2010, pp. 127-148.

Mandolessi, Silvana. "Hacia la disolución: el realismo en Sergio Chejfec." Imágenes y realismos en América Latina, Simposio Internacional, Leiden, 29 de septiembre - 1 de octubre 2011, editado por Miguel Caballero Vázquez, Luz Carranza Rodríguez y Cristina Soto vam der Plas.

https://imagenesyrealismosleiden.files.wordpress.com/2012/01/hacia-ladisolucic3b3n-el-realismo-en-sergio-chejfec.pdf. 21 noviembre 2017.

Olalquiaga, Celeste. "Biografía íntima de la plaza Altamira." 1999. Fervor de Caracas. Una antología literaria de la ciudad, selección y prólogo de Ana Teresa Torres, Fundavag Ediciones, 2015, pp. 204-209.

Pantin, Yolanda. "A veces.” 2007. Fervor de Caracas. Una antología literaria de la ciudad, selección y prólogo de Ana Teresa Torres. Fundavag Ediciones, 2015, pp. 424-427.

Puppo, María Lucía y Graciela Queirolo. "Correspondencias y tensiones en la relación palabra/imagen la cultura latinoamericana." MERIDIONAL. Revista Chilena de Estudios Latinoamericanos, núm. 9, mayo-octubre, 2017, pp. 7-26.

Rancière, Jacques. El reparto de lo sensible. Estética y política. 2000. Traducción de Mónica Padró, Prometeo libros, 2014.

—. El destino de las imágenes. 2009. Traducción de Lucía Vogelfang y Matthew Gajdowski, Prometeo Libros, 2011.

- El espectador emancipado. 2008. Traducción de Ariel Dilon, Manantial, 2010.

Soto Calderón, Andrea. El discurso sobre las imágenes en el pensamiento de Jacques Rancière. Tesis doctoral, Universidad Autónoma de Barcelona, 2016.

http://www.tdx.cat/bitstream/handle/10803/368563/asc1de1.pdf?sequenc e=1. 23 noviembre 2017.

Tinoco Guerra, Antonio. "Arturo Uslar Pietri y el antipositivismo en Venezuela." Utopía y praxis latinoamericana, vol. 15, núm. 48, 2010, pp. 97-105. 
Torres, Ana Teresa. "Caracas: Itinerario sentimental." Fervor de Caracas. Una antología literaria de la ciudad, selección y prólogo de Ana Teresa Torres, Fundavag Ediciones, 2015, pp. 19-31.

Uslar Pietri, Arturo. "Caracas de Venezuela." 1965. Fervor de Caracas. Una antología literaria de la ciudad, selección y prólogo de Ana Teresa Torres, Fundavag Ediciones, 2015, pp. 56-68.

Vásquez Suárez, Dámaris. "Palabra de mujer: una mirada a la poesía de Yolanda Pantin.” Letras, vol. 51, núm. 79, 2009, pp. 63-88. 